\title{
The Impact of Print vs. Digital Resources on Moroccan University Students' Reading Habits, Uses, and Preferences
}

\section{L'impact des ressources imprimées versus numériques sur les habitudes, les objectifs et les préférences de lecture chez les étudiants universitaires marocains}

Maryem Larhmaid ${ }^{1}$

${ }^{1}$ Faculty of Education, Mohammed V University in Rabat, Morocco

\begin{abstract}
The widespread use of digital resources, the Internet and the development of technology have brought several significant changes in reading practices, preferences and use among information consumers. Readers of the $21^{\text {st }}$ century have many options for reading thanks to the rapid growth of electronic-based reading materials, instead of printed ones, such as online newspapers, electronic books, digital encyclopedias, and online academic journals, as well as the expansion of e-book readers. All of these have contributed to changing readers' reading strategies, reading preferences, and attitudes toward the act of reading. In the field of academia, for instance, there has been a tremendous shift from paper-based reading to screen-based reading. Given the fact that digital devices have become pervasive, and that reading has recently become a digital activity, this article proposes the need to investigate the impact of print $v s$. digital reading materials on Moroccan undergraduate students' reading behaviors, preferences and use.
\end{abstract}

Résumé. L'utilisation des ressources numériques, Internet et le développement des technologies ont apporté plusieurs changements importants dans les pratiques de lecture et les comportements chez les consommateurs d'informations. Les lecteurs du $21 \mathrm{e}$ siècle ont de nombreuses options de lecture grâce à la disponibilité croissante de matériels de lecture électroniques plutôt qu'imprimés, tels que les journaux en ligne, les livres électroniques, les encyclopédies numériques et les revues universitaires en ligne, ainsi que l'expansion des lecteurs de livres électroniques. Tous ces facteurs ont contribué à changer les stratégies de lecture des lecteurs, leurs préférences et leurs attitudes à l'égard de l'acte de lecture. Dans le domaine universitaire, par exemple, il y a eu un passage conséquent de la lecture papier à la lecture basée sur l'écran. Compte tenu

\footnotetext{
${ }^{\text {a }}$ Corresponding author: mlarhmaid@yahoo.fr
} 
du fait que les appareils numériques sont devenus omniprésents et que la lecture est récemment devenue une activité numérique, cet article propose d'étudier l'impact des ressources imprimées et des ressources électroniques sur les comportements, les usages et les préférences de lecture des étudiants marocains.

\section{Introduction}

The activity of reading has undergone, recently, some technological changes. A huge number of reading materials are available nowadays in electronic form, and many options are available for those who want to read something digitally. One may read from a standard computer screen, a tablet computer, a smartphone, a laptop or a reading specific device, such as the Amazon Kindle; or, one may simply print out the relevant material and read on paper.

Digital technology has become an integral part of today students' daily life, and it is changing their ways of thinking, learning and perceptions. These digital technologies consist of a set of mobile devices (e.g., iPads, notebooks, and tablets), desktop computers, and recording devices, etc. Students, accordingly, use digital technologies to perform a number of learning activities, such as accessing reading materials, sending emails, reading e-journals and e-books, taking online surveys, and participating in online course discussions. These activities are not limited to learning situations, but also over social environments as more students, nowadays, may use new technologies for leisure and entertainment activities, such as chatting, blogging, watching movies, listening to music, and reading newspapers and magazines.

As a result, educational institutions are taking advantage of the development of digital technologies in order to engage their students with up-to-date modes of teaching and learning. One such mode is the use of digital-based reading materials, which accommodates students' reading interests, as well as being more accessible, and portable. As digital technology continues to grow and plays a key role in students' academic performance, very little is known about reading habits, preferences and use of print and electronic resources in the Moroccan higher education learning contexts

This study, in this respect, attempts to investigate the extent to which undergraduate students of ENSET- Mohammedia, University Hassan II, use print and digital resources. Another purpose of this investigation is to examine the effect of subject-discipline on students' reading preferences and use of print and electronic resources. This study also seeks to focus on digital reading habits as well as preferences for print and electronic resources among undergraduate students of ENSET-Mohammedia. Studying these issues would enable us to have a better understanding of the changing patterns of print and digital reading among Moroccan undergraduate students in the era of digital devices.

\section{Research background}

\subsection{Traditional reading and electronic reading}

Over the last few years, a great deal of studies has been conducted to investigate people's preferences for and attitudes toward print and digital resources. Most of these investigations were undertaken in the academic environment with special focus given to surveying graduate students and faculty. (e.g., Liu, 2006; Smith, 2003; Lenares, 1999; Dillon \& Hahn, 2002). 
Traditionally, reading is generally defined as an 'active', 'constructive', 'meaningmaking' process (Goldsmith, 2015; Graesser, 2007; Kintsch \& Kintsch, 2005; McNamara, 2012), whereby the text, the reader and the activity are of paramount importance (Alexander \& Jetton, 2002, Pearson, 2001). Recently, the activity of reading has been reshaped by the expansion of screen-based technologies and reading devices such as ereaders (e.g. Kindle) and tablets (e.g. iPad). All these technologies bring new affordances, when compared with traditional print reading. Hence, reading is undergoing a massive change as new digital technologies continue to expand and bring new characteristics that seek to afford the reader the ease of access, portability and storage of thousands of books and documents in a small mobile device.

In the last few years, the increasing use of electronic devices by university students and adults for academic purposes (e.g., expository text in textbooks, academic journals, research papers, and websites), as well as for pleasure purposes (e.g., novels, newspapers, magazines) (Pew Research Center, 2012) is due to the rapid shift in reading from paper toward electronic formats. The year 2005 is notable, in the history of literacy, whereby the one-billionth individual started using digital technologies to read online. (de Argaez, 2006; Internet World Stats: Usage and Population Statistics, n.d.).

Text digitization has important effects on academic environments. That is to say, learning can be impacted by both the format of the text, and the medium through which the text is consumed (Mayer et al., 2001; Morineau et al., 2001; Vygotsky, 1978). Boroughs (2010), for instance, argues that screen-based technologies and digital reading devices have the potential to affect the way(s) college and university students perceive and engage with books. This means that, students reading digital-based materials may exhibit different states of mind, attitudes and perceptions toward the subject matter.

\subsection{Digital literacy}

In the field of education, $21^{\text {th }}$ century technologies have generated a new type of literacy, and therefore, new terms have emerged along the way (e.g., digital literacy, digital learning). Today's generations are often tech-savvy; they are familiar with digital media and generally know how to navigate, access, and share digital information (Ting, 2015). Anstey and Bull (2006) note that literate individuals in the $21^{\text {th }}$ century do not only need to be able to search, and to manage digital information, but they also need to have [at their disposal] a large repertoire of literacy skills, and strategies that allow them to navigate "the ever-changing landscape" of new literacies. Similarly, Greene, Yu and Copeland (2014) support the notion that to be digitally literate, one does not just need to know how to use the new technologies to find information on the web, but also to scrutinize, integrate and assemble information from different digital and print sources. According to the European Framework for digital literacy, digital literacy is defined as the following:

"Digital literacy is the awareness, attitude and ability of individuals to appropriately use digital tools and facilities to identify, access, manage, integrate, evaluate, analyze and synthesize digital resources, construct new knowledge, create media expressions, and communicate with others, in the context of specific life situations, in order to enable constructive social action; and to reflect upon this process." (Martin, 2006: 135; cited in Tang \& Chaw, 2016: 56).

The above-cited definition sheds light on the importance of individuals' ability to construct meaning and connect with one another through digital technologies. It also emphasizes individuals' ability to search, evaluate, and synthesize information using digital resources. Since readers of the $21^{\text {th }}$ century do not solely limit themselves to either print or digital media, but use both, the following section seeks to understand the possible differences, advantages and imitations of print and digital reading. 


\subsection{Digital and print reading: advantages and limitations}

Print and digital media have specific advantages; and limitations, as different readers use various reading formats in different contexts. Perhaps, one major advantage of print reading is that it offers readers access to the text in its entirety. This access is built up on both visual and tactile cues, whereby the reader can see, as well as "tactilely feel the spatial and physical dimensions" of the text. By contrast, readers using digital media are restricted by the limited access, and the non-physicality of the text; they can access only one page, but not the entire text, at any given time of reading (Mangen, 2010; Sellen \& Harper, 2002).

Studies such as Hillesund's (2010) and Mangen's (2008) posit that digital reading is dominated by 'shallow', 'discontinuous', and 'fragmented' forms of reading (e.g. browsing, scanning, skimming), and the digital environment often leads to lower comprehension compared to printed text. Likewise, Goldsmith (2011) found that people perceive print media as more suitable for effortful learning; whereas, the electronic media is best suited for fast and shallow reading of short texts such as news, emails, forum notes...etc.

The digital revolution has also contributed to partial predominance of online reading over traditional print reading in certain situations (but not in all situations) by providing powerful advantages such as non-linearity, immediacy of searching words in the text, immediacy of accessing information, and the convergence of text and images (Landow, 1992; Lanham, 1993; Murray, 1997; Ross, 2003).

Alongside the aforementioned affordances and limitations of digital reading, studies such as Zickuhr et al. (2012) claim that people who own electronic devices and e-readers "read on average twice as many books as those who read only in print" (cited in Singer, 2016). Moreover, Rideout et al. (2010) found that the amount of time spent on reading printed texts has decreased about 5 minutes between 1999 and 2009 among young users of age 8 to 18 , suggesting the predominance of digital reading over print reading. All of these advantages have been cited as major incentives of the recent technological shift of the venerable activity of reading.

Given the advances in screen-based media and digital reading devices, a huge number of Moroccan university students, as well as adults are recently reading online. As a matter of fact, the Moroccan national telecommunication agency (ANRT) conducted recent surveys in 2015 and 2016, and found that more than half of the Moroccan households own a computer, or a tablet $(54.8 \%$ ), whereby tablets constitute $15 \%$ (i.e. more than a quarter of the number of computers), and computers constitute $55 \%$ of computing devices. The ANRT also argued that nearly 15 million smartphones are in use, and 12 million of Moroccans living in urban areas have access to the Internet, and spend approximately $13 \mathrm{~h}$ per week online.

The present study explores a selection of Moroccan students' reading behaviors, preferences and use of print vs. digital resources from different perspectives.

\section{Method}

\subsection{Participants and setting}

Participants of this study were asked to report on their reading behaviors, preferences for and attitudes toward the use of digital documents, vis-à-vis, print documents by selfreported measures of their overall reading experience, including their academic related reading and leisure reading. The current study uses a convenience sample of 97 undergraduate students enrolled in three different disciplines at ENSET-Mohammedia, Hassan II University. The sample was $55.8 \%$ male with a mean age of $20.96(S D=2.34)$ 
years. The sample represented a variety of three disciplines, notably software engineering (37.9\%), electrical engineering and industrial control of systems (GECSI) (31.6\%), and finance and accounting (30.5\%). Among the 97 questionnaires returned, 95 are complete and 2 are incomplete. The results of the 95 completed questionnaires are presented in tables 1-8 below.

This investigation was conducted in September/November 2017, whereby participants were asked to respond to a cluster of questions designed to gather information about screenbased as well print-based reading habits, preferences and frequency of using print and electronic resources. The questionnaire was mainly about the following key points:

Demographic information: the first step in this investigation was to reveal participants' gender, field of study, and age.

Reading time: as a next step, we asked participants of this study about time spent on reading print and digital documents/resources (i.e. more time, less time, do not know).

Medium usage: in order to ascertain students' familiarity with digital materials, two types of questions were inquired: (1) students were asked about which type of reading medium (i.e. print or digital) they use for academic and for pleasure reading. (2) And how frequently they use print and digital resources for pleasure and academic reading.

Reading habits: respondents were also asked some questions about how they would describe their reading process in print and/or digitally in relation to browsing and scanning, sustained attention, in-depth reading, information selection, non-linear reading, and keyword searching, multitasking and highlighting.

Medium preference: after completing the reading pattern section, we asked students to report on their favorite reading platform (i.e. print, digital, or both).

These questions were designed with the aims of achieving a deeper understanding of the extent to which Moroccan undergraduate students use and opt for print vs. digital resources for academic and pleasure readings, and exploring whether this use of print and digital resources are determined by subject discipline. Moreover, the specific questionnaire items cited above were guided by a need to find out reading habits and preferences of reading formats (i.e. print vs. digital) among Moroccan university students in an increasingly intensive digital environment. With this in mind, special attention was paid to participants' long-term memories in the design of the questionnaire and answering items (i.e. more time, less time, do not know). This means, in case respondents do not remember specific changes about their overall reading time and reading habits, they can simply select the 'do not know' answering category.

For the purpose of this study, participants were informed about the main objectives of the investigation. In this regard, they were asked to fill out the questionnaires beforehand based on their own experiences with using print and digital resources for academic reading, as well as for leisure reading. For the sake of concreteness, the author provides a copy of the sample items used in this study at the end of the paper (see appendix).

\section{Results}

\subsection{Time allocated on print and digital reading}

Table 1 provides basic summary statistics of the percentage of time devoted to reading print and electronic materials across the three disciplines. Overall, an average of nearly 54.5 percent of the 66 respondents $(61.1 \%$ in software engineering and $46.4 \%$ in electrical engineering) reported that they spend "more time" on reading digital materials than those in finance and accounting (3.4\%). Table 1 also shows that 77.8 percent of respondents in software engineering, and 60 percent in electrical engineering spend "less time" on print 
reading compared to 44.8 percent in finance and accounting who spend "less time" on digital reading. Also related, 65.5 percent of respondents in finance and accounting report that they "don't know" how much time they spend on print reading, compared to 13.3 percent of respondents in electrical engineering and 8.3 percent in software engineering who "do not know" how much time they spend on digital reading. In addition, data analysis of this study indicates a positive correlation between participants' age and time devoted to print reading $(\mathrm{r}=.35, \mathrm{n}=95, \mathrm{p}<.0005)$ (i.e. increased age is associated with increased amount of time spent on print reading).

\begin{tabular}{|l|c|c|c|c|c|c|}
\hline \multirow{2}{*}{$\begin{array}{l}\text { Type of } \\
\text { reading } \\
\text { formats }\end{array}$} & \multicolumn{2}{|c|}{$\begin{array}{c}\text { Software engineering } \\
(\mathbf{n = 3 6})\end{array}$} & \multicolumn{2}{|c|}{$\begin{array}{c}\text { Electrical engineering } \\
(\mathbf{n = 3 0})\end{array}$} & \multicolumn{2}{|c|}{$\begin{array}{c}\text { Finance and accounting } \\
(\mathbf{n = 2 9 )}\end{array}$} \\
\cline { 2 - 7 } & print & digital & print & digital & print & digital \\
\hline $\begin{array}{l}\text { More } \\
\text { time }\end{array}$ & $5(13.9 \%)$ & $22(61.1 \%)$ & $6(20 \%)$ & $14(46.7 \%)$ & $3(10.3 \%)$ & $1(3.4 \%)$ \\
\hline Less time & $28(77.8 \%)$ & $11(30.6 \%)$ & $18(60 \%)$ & $12(40 \%)$ & $7(24.1 \%)$ & $13(44.8 \%)$ \\
\hline $\begin{array}{l}\text { Do not } \\
\text { know }\end{array}$ & $3(8.3 \%)$ & $3(8.3 \%)$ & $6(20 \%)$ & $4(13.3 \%)$ & $19(65.5 \%)$ & $15(51.7 \%)$ \\
\hline
\end{tabular}

Table 1. Print and digital reading time

\subsection{Type of reading formats respondents use for academic and pleasure reading}

In our sample, electronic media are more used than print media for academic and pleasure reading. Table 2 indicates that 73.6 percent of all respondents use electronic media as a reading format for both academic and pleasure reading, compared to only 21.5 percent who use print media. Moreover, our results show that 4.3 percent claim that they use "both" print and digital media for academic and pleasure reading. To investigate which type of reading format is used for academic and for pleasure reading, our findings suggest that there is a significant difference across respondents of the three disciplines. Put differently, nearly 86.1 percent of respondents in software engineering report that they use electronic media for academic reading, compared to 76.7 percent in electrical engineering, and 82.2 percent in finance and accounting who use electronic media for pleasure reading. On the other hand, 40.0 percent of respondents in electrical engineering, and 24.1 percent in finance and accounting report that they use print media for academic reading, compared to 25 percent in software engineering who use print media for pleasure reading. 


\begin{tabular}{|l|c|c|c|c|c|c|c|}
\hline \multirow{2}{*}{$\begin{array}{l}\text { Type of } \\
\text { reading } \\
\text { formats }\end{array}$} & \multicolumn{2}{|c|}{$\begin{array}{c}\text { Software engineering } \\
(\mathbf{n = 3 6})\end{array}$} & \multicolumn{2}{|c|}{$\begin{array}{c}\text { Electrical engineering } \\
(\mathbf{n = 3 0})\end{array}$} & \multicolumn{2}{|c|}{$\begin{array}{c}\text { Finance and accounting } \\
(\mathbf{n = 2 9})\end{array}$} & $\begin{array}{c}\text { Total } \\
(\mathbf{n = 9 5})\end{array}$ \\
\cline { 2 - 7 } & academic & pleasure & academic & pleasure & academic & pleasure & \\
\cline { 1 - 6 } $\begin{array}{l}\text { Print } \\
\text { media }\end{array}$ & $1(2.8 \%)$ & $9(25 \%)$ & $12(40 \%)$ & $7(24.1 \%)$ & $7(24.1 \%)$ & $5(17.2 \%)$ & $21.5 \%$ \\
\hline $\begin{array}{l}\text { Electronic } \\
\text { media }\end{array}$ & $31(86.1 \%)$ & $25(69.4 \%)$ & $16(53.3 \%)$ & $23(76.7 \%)$ & $\begin{array}{l}21(72.4 \\
\%)\end{array}$ & $\begin{array}{l}24(82.8 \\
\%)\end{array}$ & $73.6 \%$ \\
\hline Both & $4(11.1 \%)$ & $2(5.6 \%)$ & $2(6.7 \%)$ & 0 & $1(3.4 \%)$ & 0 & $4.3 \%$ \\
\hline
\end{tabular}

Table 2. Type of reading formats

\subsection{Frequency of using print and digital formats for studying}

\begin{tabular}{|c|c|c|c|c|c|c|c|c|}
\hline \multirow[t]{2}{*}{ Frequency } & \multicolumn{2}{|c|}{$\begin{array}{l}\text { Software engineering } \\
(\mathrm{n}=\mathbf{3 6})\end{array}$} & \multicolumn{2}{|c|}{$\begin{array}{l}\text { Electrical engineering } \\
\qquad(\mathbf{n}=\mathbf{3 0})\end{array}$} & \multicolumn{2}{|c|}{$\begin{array}{c}\text { Finance and } \\
\text { accounting } \\
(\mathrm{n}=29)\end{array}$} & \multicolumn{2}{|c|}{$\begin{array}{l}\text { Total } \\
(\mathbf{n}=95)\end{array}$} \\
\hline & $\begin{array}{l}\text { Print } \\
\text { resources }\end{array}$ & $\begin{array}{l}\text { Digital } \\
\text { resources }\end{array}$ & $\begin{array}{l}\text { Print } \\
\text { resources }\end{array}$ & $\begin{array}{l}\text { Digital } \\
\text { resources }\end{array}$ & $\begin{array}{l}\text { Print } \\
\text { resources }\end{array}$ & $\begin{array}{l}\text { Digital } \\
\text { resources }\end{array}$ & Print & Digital \\
\hline Very often & $\begin{array}{l}3 \\
(8.3 \%)\end{array}$ & $\begin{array}{l}20 \\
(55.6 \%)\end{array}$ & $\begin{array}{l}4 \\
(16.7 \%)\end{array}$ & $\begin{array}{l}11 \\
(36.7 \%)\end{array}$ & $\begin{array}{l}2 \\
(6.9 \%)\end{array}$ & $\begin{array}{l}7 \\
(24.1 \%)\end{array}$ & $9.4 \%$ & $40.0 \%$ \\
\hline Frequently & $\begin{array}{l}9 \\
(25 \%)\end{array}$ & $\begin{array}{l}10 \\
(27.8 \%)\end{array}$ & $\begin{array}{l}13 \\
(43.3 \%)\end{array}$ & $\begin{array}{l}16 \\
(53.3 \%)\end{array}$ & $\begin{array}{l}11 \\
(37.9 \%)\end{array}$ & $\begin{array}{l}13 \\
(44.8 \%)\end{array}$ & $34.7 \%$ & $44.2 \%$ \\
\hline Occasionally & $\begin{array}{l}23 \\
(63.9 \%)\end{array}$ & $\begin{array}{l}4 \\
(11.1 \%)\end{array}$ & $\begin{array}{l}12 \\
(40.0 \%)\end{array}$ & $\begin{array}{l}2 \\
(6.7 \%)\end{array}$ & $\begin{array}{l}10 \\
(34.5 \%)\end{array}$ & $\begin{array}{l}3 \\
(10.3 \%)\end{array}$ & $47.3 \%$ & $9.4 \%$ \\
\hline Never & $\begin{array}{l}1 \\
(2.8 \%)\end{array}$ & $\begin{array}{l}2 \\
(5.6 \%)\end{array}$ & 0 & $\begin{array}{l}1 \\
(3.3 \%)\end{array}$ & $\begin{array}{l}6 \\
(20.7 \%)\end{array}$ & $\begin{array}{l}6 \\
(20.7 \%)\end{array}$ & $7.3 \%$ & $9.4 \%$ \\
\hline
\end{tabular}

Table 3. Print and digital platforms frequency of use

Digital resources are more frequently used than print resources for studying. Table 3 reveals that 84.2 percent of all respondents use digital materials very often" or "frequently" for studying, compared to only 44.1 percent who "very often" or "frequently" use print resources. The use of print and digital materials for studying varies across disciplines. Simply put, students in software engineering and in electrical engineering use digital resources more frequently than those in finance and accounting. More specifically, about 83.4 percent of respondents in software engineering, and 90 percent in electrical engineering report that they "very often" or "frequently" use digital resources for studying, compared to only 72.4 percent in finance and accounting who "frequently" or "occasionally" use print resources for studying.

To investigate the impact of subject-discipline on frequency of using print and digital resources, data analysis of this research indicates that there is a significant difference among different subject disciplines in terms of using print resources $\left(\chi^{2}=16.967, \mathrm{ddl}=6, \mathrm{p}\right.$ $=0.009)$, as well as in terms of using digital resources $\left(\chi^{2}=12.836, \mathrm{ddl}=6, \mathrm{p}=0.046\right)$. As 
far as this study is concerned, we argue that subject discipline affects students' frequency of using print and digital resources for studying,

\subsection{Participants' electronic reading habits}

\begin{tabular}{|l|c|c|c|}
\hline Percentage of time spent on & Increasing & Decreasing & Don't know \\
\hline Browsing and scanning & $(50) 52.6 \%$ & $(30) 31.6 \%$ & (15) $15.8 \%$ \\
\hline Keyword searching & $(31) 33.0 \%$ & $(44) 46.8 \%$ & (18) $19.1 \%$ \\
\hline Reading selectively & $(48) 50.5 \%$ & (17) $17.9 \%$ & (30) $31.6 \%$ \\
\hline Non-linear reading & (33) $35.5 \%$ & (42) $45.2 \%$ & (18) $19.4 \%$ \\
\hline Sustained attention & (50) $52.6 \%$ & (28) $29.5 \%$ & (17) $17.9 \%$ \\
\hline In-depth reading & (44) $46.3 \%$ & (36) $37.9 \%$ & (15) $15.8 \%$ \\
\hline
\end{tabular}

Table 4. Digital reading habits

a) More browsing/scanning and less keyword searching. As shown in table 4, descriptive statistics of our research indicate that about 52.6 percent of the participants in this study report that a considerable percentage of time is spent on browsing and scanning digital documents. On the other hand, about 46.4 percent claim that they are less likely to search for keywords when they read digital documents.

b) Increasing selective reading and decreasing non-linear reading. More than half of the respondents in this study $(50.5 \%)$ note that they are selective readers in the digital environment; whereas, 45.2 percent report that their non-linear reading (i.e. skipping lines or portions of text while reading) is "decreasing" when reading digitally.

c) Increasing sustained attention and in-depth reading. Roughly speaking, 52.6 percent of the participants in this study indicate increased attention, as well as increased in-depth reading $(46.3 \%)$ during electronic reading.

\subsection{Frequency of multitasking in print and digital documents}

\begin{tabular}{|l|c|c|}
\hline Frequency & Print materials & Digital materials \\
\hline Very often & $4(4.2 \%)$ & $21(21.1 \%)$ \\
\hline Frequently & $23(24.2 \%)$ & $36(37.6 \%)$ \\
\hline Occasionally & $33(34.7 \%)$ & $23(24.2 \%)$ \\
\hline Never & $35(36.8 \%)$ & $15(15.8 \%)$ \\
\hline Total & 100.0 & 100.0 \\
\hline
\end{tabular}

Table 5. A comparison of multitasking in print and digital materials 
4.6 Frequency of highlighting print and digital materials

\begin{tabular}{|l|c|c|}
\hline Frequency & Print materials & Digital materials \\
\hline Very often & $17(17.9 \%)$ & $19(20.0 \%)$ \\
\hline Frequently & $39(41.1 \%)$ & $35(36.8 \%)$ \\
\hline Occasionally & $21(22.1 \%)$ & $24(25.3 \%)$ \\
\hline Never & $18(18.9 \%)$ & $17(17.9 \%)$ \\
\hline Total & 100.0 & 100.0 \\
\hline
\end{tabular}

Table 6. A comparison of highlighting print and digital materials

According to Table 5, approximately 59 percent of the participants in this survey report that they "very often", or "frequently" multitask when using digital resources, compared to only 24.4 percent who "very often", or "frequently" multitask when using print resources. It is also interesting to note that about 37 percent of the respondents report that that they "never" multitask with print materials, while about 16 percent claim that they "never" multitask when reading digitally.

As indicated in Table 6, the pattern of highlighting print and digital resources is quite similar among participants of this study. In other words, our findings suggest that our respondents highlight digital materials $(57 \%)$ the same way they highlight print materials (about $59 \%$ ).

\subsection{Frequency of printing electronic materials}

\begin{tabular}{|l|c|c|c|c|}
\hline Frequency & $\begin{array}{c}\text { Software } \\
\text { engineering } \\
(\mathbf{n = 3 6})\end{array}$ & $\begin{array}{c}\text { Electrical } \\
\text { engineering } \\
(\mathbf{n = 3 0})\end{array}$ & $\begin{array}{c}\text { Finance and } \\
\text { accounting } \\
(\mathbf{n = 2 9})\end{array}$ & $\begin{array}{c}\text { Total } \\
(\mathbf{n}=\mathbf{9 5})\end{array}$ \\
\hline Very often & 0 & $1(3.3 \%)$ & $2(6.9 \%)$ & $3(3.2 \%)$ \\
\hline Frequently & $17(47.2 \%)$ & $7(23.3 \%)$ & $7(24.1 \%)$ & $31(32.6 \%)$ \\
\hline Occasionally & $12(33.3 \%)$ & $19(63.3 \%)$ & $13(44.8 \%)$ & $44(46.3 \%)$ \\
\hline Never & $7(19.4 \%)$ & $3(10.0 \%)$ & $7(24.1 \%)$ & $17(17.9 \%)$ \\
\hline
\end{tabular}

Table 7. Frequency of printing out digital materials

Even though 46.3 percent (33.3\% in software engineering, $63.3 \%$ in electrical engineering, and 44.8 percent in finance and accounting) report that they "occasionally" print out digital materials for reading, the frequency of printing out varies by discipline. Table 7 shows that 47.2 percent of respondents in software engineering note that they "frequently" print out electronic documents compared to 63.3 percent in electrical engineering and 44.8 percent in finance and accounting who note that they "occasionally" print out electronic documents, in addition to only 6.9 percent in finance and accounting who report "very often" printing out digital documents. However, none of the respondents in software engineering report "very often" printing out digital documents. Further, an average of only 17.9 percent of the participants in this investigation mention that they "never" print out digital materials. 
4.8 Frequency of reading media

\begin{tabular}{|l|c|c|c|c|}
\hline $\begin{array}{l}\text { Reading } \\
\text { formats }\end{array}$ & $\begin{array}{c}\text { Software } \\
\text { engineering } \\
(\mathbf{n = 3 6})\end{array}$ & $\begin{array}{c}\text { Electrical } \\
\text { engineering } \\
(\mathbf{n = 3 0})\end{array}$ & $\begin{array}{c}\text { Finance and } \\
\text { accounting } \\
(\mathbf{n = 2 9})\end{array}$ & $\begin{array}{c}\text { Total } \\
(\mathbf{n = 9 5})\end{array}$ \\
\hline Print media & $8(22.2 \%)$ & $11(37.9 \%)$ & $5(17.2 \%)$ & $24(24.5 \%)$ \\
\hline $\begin{array}{l}\text { Electronic } \\
\text { media }\end{array}$ & $18(50.0 \%)$ & $6(20.7 \%)$ & $17(58.6 \%)$ & $41(43.6 \%)$ \\
\hline Both are good & $10(27.8 \%)$ & $12(40.0 \%)$ & $7(24.1 \%)$ & $29(30.5 \%)$ \\
\hline
\end{tabular}

Table 8. Types of reading media respondents prefer for reading

According to Table 8 , we notice that 43.6 percent of the participants in this study report "electronic media" as their favorite reading platform, compared to only 24.5 percent who prefer "print media", and 30.5 percent who prefer both reading formats. More specifically, half of the respondents in software engineering (50.0\%) and approximately 59 percent in finance and accounting mention that they favor digital reading formats; whereas, about 38 percent of participants in electrical engineering note a preference for print reading formats. To examine the importance of subject discipline to choice of reading formats, the analysis of the present study shows that there is a significant relation between students' subject discipline and preference of reading media $(\phi=0.319, p=0.048)$.

\section{Discussion}

The present study used a convenience sample of 95 undergraduate students enrolled in three different majors at ENSET-Mohammedia, in an attempt to investigate the impact of print and digital resources on students' reading habits, preferences and use. Our results indicate that undergraduate students spend an increased amount of time on reading digital documents than reading print documents. This finding is consistent with prior research studies such as Liu's (2005) through which $83.2 \%$ of the participants (including young and adults) in a survey reported that they spend more time on reading electronic documents, compared to 67.3 percent of respondents who spend more time on reading print documents, suggesting a trend toward the predominance of digital reading. Perhaps the main factors that contribute to the increase in digital reading time are: (1) information explosion, (2) development of digital technology, and (3) the widespread use of electronic devices. Interestingly enough, this study found that students' age level is positively correlated with the percentage of time spent on print reading than on digital reading. It is conceivable that younger readers prefer to receive information in digital media, compared to adults who still use the old-fashioned way in reading (Strouse, 2004).

Findings of the current study also showed that the majority of the respondents $(73.6 \%)$ reported using electronic media more than print media for academic and pleasure reading. However, choosing between print and digital media for academic and for pleasure reading varies among disciplines. In other words, students in electrical engineering and finance and accounting report using electronic media for pleasure reading, and using print media for academic reading. On the other hand, participants in software engineering report using print media for pleasure reading and using electronic media for academic reading. These inconsistent results among participants of this research have been documented in previous studies. For instance, in surveying undergraduate library users at the University of Toronto, Dilevko and Gottlieb (2002) found that although undergraduate students used electronic resources for their assignments and essays, traditional print resources (e.g. books and 
printed journals) were integral parts of their research due to their reliability and permanent accessibility (cited in Liu, 2006). In this respect, we can postulate that, despite the fact that digital reading of academic texts has recently become a common practice among university students, reading digitally may be suited only for shallower reading such as reading novels and magazines; whereas, effortful and engaged reading is best supported by reading in print. In support of this contention, Foasberg (2014) argued that subjects tended to use electronic formats for shorter and non-academic readings; however, they chose print formats when reading for class-related tasks.

Despite the aforementioned disadvantages of digital reading, participants of this study report a high frequency of using electronic materials than using print materials for studying. This finding is surprisingly inconsistent with previous claims of using print documents more frequently for academic reading than for pleasure reading. This inconsistency could be due to commonly cited factors such as ease of access, low cost of electronic documents (compared to print), searching, storage and portability. These benefits have been reported as major incentives for choosing digital texts over print texts (Liew et al., 2000; Sathe et al., 2002; Stephens, 2010; Creel, 2008).

Based on the high frequency of using digital texts instead of print, this study sought to determine the reading habits and practices of respondents in using these electronic materials. In this respect, the results imply that students' electronic reading is characterized by more browsing, more scanning, and less keyword searching. Such reading habits are likely to occur with the increasing flow of digital information, through which readers feel incapable of keeping pace with the available literature. In this way, they are forced to browse and skim web pages as if they were skimming newspapers (i.e. skimming headings) (Liu, 2005).

Browsing and scanning might indeed be effective ways to filter, and look for needed information during reading in the hypertext environment. For instance, in 2000, the Poynter Institute conducted a study and found that most web users "do a lot of brief scanning, foraging quickly through many articles, summaries, but when their interests is caught they will dive into a particular topic or article in depth" (cited in Liu, 2005). Keyword searching, as an online search-reading tool, is also popular and widely adopted in the digital environment. Surprisingly, respondents of this study report that they are less likely to use keyword searching as a way to locate needed information. Such unlikelihood could mean that our participants have at their disposal an enriching set of skills that enable them to cope with the overwhelming amount of information in the digital environment "digital natives" (Prensky, 2004). What is more, our respondents are selective readers in the digital environment. With the excessive use of the Internet and the rapid growth of digital information, students of this investigation are very likely to be more alert and more attentive to the trustworthiness and credibility of the information found on the web.

With the information explosion and the development of digital technologies in the $21^{\text {st }}$ century, non-linear reading, a new reading pattern in which the reader generally scrolls frequently between portions of the text, has emerged among users of digital texts. Though non-linear reading is a feature of digital environment par excellence, participants of this study have reported reading digital texts in a linear order (i.e. traditional mode of reading). As we noted earlier, this unusual reading pattern among our students might also be due to their reading skills and familiarity with using digital media. Such familiarity could also be a key factor to their increased sustained attention and increased in depth reading when reading digitally. These findings, however, are inconsistent with previous works such as Eveland and Dunwoody's (2001), which posit that readers using digital media are likely to have difficulties with attentive reading because of multiple texts, multiple hyperlinks, as well as frequent scrolling found in the digital environment (Liu, 2005). 
Also related, multitasking is a reading attribute commonly associated with digital than with print reading, as the majority of participants of this study note that they are more likely to multitask when reading digitally than when reading in print. In the same vein, Liu et al. (2009) claimed that readers working on a digital device tended to switch activities every 3 to 10 minutes and argued that frequent multitasking could lead to lower engagement with the text (cited in Singer, 2016). It is also conceivable that Internet access combined with multiple information sources and excessive use of social media may increase instances of multitasking among readers (Wallis, 2010; Rowlands et al. 2008). Highlighting is another reading pattern commonly associated with print media more than digital media. To demonstrate, Liu (2005) posits that highlighting electronic documents was not a common practice among users of electronic documents. Nevertheless, this research paper shows that highlighting digital texts is indeed a common practice among participants of this study. Based on these results, we postulate that our respondents are "tech savvy", armed with necessary skills and strategies to cope with screen reading.

The question to the frequency of printing out digital materials for reading has generated contradictory results among participants of this study, as students in software engineering report printing out digital documents more frequently than their counterparts in electrical engineering, and finance and accounting, who note "occasionally" printing out electronic materials. These findings are apparently inconsistent with previous self-reports through which participants in software engineering have claimed that they use electronic platforms more frequently than using print for course-related works. In a similar study, Liu (2005) argue that although respondents spent a considerable amount of time on electronic media, they tended to print out digital documents when reading serious papers. By the same token, respondents in other studies claim that printing out electronic documents not only facilitate annotations but also make comparisons among all gathered sources easier (Dilveko \& Gottlieb, 2002; cited in Liu, 2006).

Based on our intention to investigate the impact of subject discipline on students' preference for reading media, 50 percent of respondents in software engineering and 59 percent of respondents in finance and accounting reported that they favor digital platforms over print platforms; whereas, 40 percent of participants in electrical engineering mention a preference for both platforms (i.e. print and digital). Recent studies have also documented that students' preference for electronic resources over print resources is dependent on subject discipline (Smith, 2003; Siebenberg et al., 2004). For one, Liu (2006) found that 71.4 percent of students in library and information sciences have a strong preference for library online sources than students in business (42.4\%), computer sciences (37.1\%) and social sciences $(52.2 \%)$. The desire for a hybrid of print and digital media has also been reported in a few studies (Dilveko \& Gottlieb, 2002; Friedlander, 2002; Dillon \& Hahn, 2002; Liu, 2006).

\section{Conclusions, limitations and implications}

In summary, this investigation was motivated by the excessive use of digital devices for reading purposes in the lives of Moroccan university students. With the overwhelming amount of digital information and ease of Internet access, new reading patterns such as scanning, browsing, key word searching and skimming are likely to emerge among university students. Despite the fact that a great deal of prior research claim that digital environment seems not to be suited for in-depth reading (Mangen et al., 2013; Rideout et al., 2010; Wallis, 2010; Levine et al., 2007), this study showed that, regardless of subject discipline, digital reading is increasingly adopted by Moroccan university students. Interestingly enough, the findings of this research paper imply that increased age is 
associated with increased amount of time allocated on print reading, suggesting that readers' age plays a key role in choosing between print and digital reading formats.

Based on their own reading practices, this study aimed to examine Moroccan university students' reading practices in the digital age through using self-reported measures. The study beforehand targeted undergraduate students of ENSET-Mohammedia who are enrolled in three different majors notably, software engineering, electrical engineering, and finance and accounting. Results showed that, regardless of subject discipline, the majority of the participants in this study opted for digital media as the best reading platform for both academic and pleasure reading. A hybrid of print and digital materials is also desired by a considerable amount of participants in this study, which could provide users an array of multiple information sources and new access opportunities.

Among the limitations of this study is that the findings of this survey cannot be generalized over large groups of Moroccan university students, as well as cannot be generalized to all academic reading situations due to the small size sample. Therefore, further studies are required to investigate larger groups including not only undergraduate students, but also adults and graduate students in a variety of disciplines.

This study, accordingly, has come up with several recommendations and implications for education, and they are as follows:

- Follow up research is needed to examine the circumstances that affect students' choice of formats of resources along with students' perceived advantages and barriers of using digital resources in academic settings.

- Future research is also needed to investigate the impact of new digital technologies on students' reading habits in relation to language teaching.

- Further work is also required to explore the impact of different subject disciplines on students' preference for reading media.

- It is recommended to conduct additional work on the impact of the reading medium (print or digital) not only on students' cognitive processing such as reading comprehension and recall, but also on motivational and visual factors that may be implicated.

- Set guidelines for using and incorporating digital technologies/texts in reading instruction and teaching/learning environments.

- Develop an awareness of the advantages and disadvantages of using digital reading materials.

\section{Acknowledgements}

This study was supported by a grant from the National Center for Scientific and Technical Research in Rabat (CNRST-Rabat) under the funding program "the Excellence Grant for Doctorate Research". Special thanks go to Professor Taibi Nour and Professor Peter Afflerbach for their insightful remarks and feedback. The author also appreciated constructive comments from the anonymous reviewers.

\section{Bibliography}

Ackerman R. \& Goldsmith M. (2011). Metacognitive Regulation of Text Learning: On Screen Versus on Paper. Journal of Experimental Psychology: Applied, Vol. 17, p. 18-32.

Anstey M. \& Bull G. (2006). Teaching and Learning Multiliteracies: Changing times, changing literacies. Newark, DE: International Reading Association. 
Boroughs D. (2010). Bye the Book: In educational publishing, the only certainty is change. PRISM. Retrieved from http://www.prism-magazine.org/apr10/feature_01.cfm.

Calcuttawala Z. (2016). 2016 ANRT Survey: Nearly Half of All Moroccans Own a Smartphone. Retrieved from https://www.moroccoworldnews.com/2016/04/184743/2016anrt-survey-nearly-half-of-all-moroccans-own-a-smartphone/.

Creel S. (2008). Young Teens on Reading and e-Reading: A Survey. Youth Voice Advocates, Vol. 31, No. 3, p. 201-207.

de Argaez E. (Ed.) (2006). Internet world stats news, No. 14. Retrieved from http://www.internetworldstats.com/pr/edi014.htm\#3/.

Dilevko J. \& Gottlieb L. (2002). Print Sources in an Electronic Age: A Vital Part of the Research Process for Undergraduate Students. Journal of Academic Librarianship, Vol. 28, No. 6, p. 381-392.

Dillon I. F. \& Hahn K. L. (2002). Are Researchers Ready for the Electronic-Only Journal Collection? Libraries and Academy, Vol. 2, No. 3, p. 375-390.

Eveland W. P. \& Dunwoody S. (2001). User Control and Structural Isomorphism or Disorientation and Cognitive Load? Learning from the Web Versus Print. Communication Research, Vol. 28 No. 1, p. 48-78.

Foasberg N. M. (2014). Student Reading Practices in Print and Electronic Media. College \& Research Libraries, Vol. 75, No. 5, p. 705-723.

[https://crl.acrl.org/index.php/crl/article/view/16382/17828].

Friedlander A. (2002). Dimensions and Use of the Scholarly Information Environment: Introduction to a Data Set Assembled by the Digital Library Federation and Outsell, Inc., CLIR Report 11/02. Retrieved from http://www.clir.org/pubs/reports/pub110/contents.html.

Grabe W. (2009). Reading in a Second Language: Moving from theory to practice, New York: Cambridge University Press.

Greene J. A., Yu S. B. \& Copeland D. Z. (2014). Measuring Critical Components of Digital Literacy and their Relationships with Learning, Computers \& Education, Vol. 76, p. 55-69.

Hillesund T. (2010). Digital Reading Spaces: How expert readers handle books, the Web and electronic paper. First Monday, Vol. 15, No. 4.

Available at http://firstmonday.org/article/view/2762/2504.

Kintsch W. \& Kintsch E. (2005). Comprehension. In S. G. Paris \& S. A. Stahl (Eds), Children's reading: Comprehension and assessment, Mahwah, NJ: Lawrence Erlbaum, p. 71-92.

Landow G. P. (1992). Hypertext: The Convergence of Contemporary Critical Theory and Technology, Baltimore, MD: Johns Hopkins University Press.

Lanham R. A. (1993). The Electronic Word: Democracy, Technology, and the Arts, Chicago, IL: University of Chicago Press.

Lenares, D. (1999). Faculty Use of Electronic Journals at Research Institutions. In H. A. Thompson (Ed.), Racing Toward Tomorrow: Proceedings of the $9^{\text {th }}$ National Conference of the Association of College and Research Libraries. Available at http://www.ala.org/ala/acrl/acrlevents/lenares99.pdf. 
Liew C. L., Foo S. \& Chennupati K. R. (2000). A Study of Graduate Student End-Users' Use and Perception of Electronic Journals. Online Information Review, Vol. 24, No. 4, p. 302-315.

Liu A., Aamodt S., Wolf M., Gelernter D. \& Mark G. (2009). Does the Brain Like EBooks? New York Times, October 14 2009, p. 17.

[https://roomfordebate.blogs.nytimes.com/2009/10/14/does-the-brain-like-e-books/].

Liu Z. (2005). Reading Behavior in the Digital Environment: Changes in Reading Behavior over the Past Ten Years. Journal of Documentation, Vol. 61, No. 6, p. 700-712.

Liu Z. (2006). Print vs. Electronic Resources: A Study of User Perceptions, Preferences and Use. Information Processing and Management, Vol. 42, No. 2, p. 583-92.

Mangen A. (2008). Hypertext Fiction Reading: Haptics and Immersion. Journal of Research in Reading, Vol. 31, No. 4, p. 404-419.

Mangen A. (2010). Point and Click: Theoretical and Phenomenological Reflections on the Digitization of Early Childhood Education. Contemporary Issues in Early Childhood, Vol. 11, No. 4, p. 415-431.

Martin A. (2006). A European Framework for Digital Literacy, Digital Kompetanse, Vol. 2, p. 151-161.

McKnight C. (1997). "Electronic Journals: What Do Users Think of Them?", In Proceedings of the International Symposium on Research, Development and Practice in Digital Libraries. Tsukaba, Japan: University of Library and Information Science. Retrieved from http://www.dl.slis.tsukuba.ac.jp/ISDL97/proceedings/mcknight.html.

McNamara D. S. (Ed.) (2012). Reading Comprehension Strategies: Theories, Interventions, and Technologies, New York, NY: Psychology Press.

Miall D. S. \& Dobson T. (2006). Reading Hypertext and the Experience of Literature. Journal of Digital Information, Vol. 2, No. 1 .

Retrieved from https://journals.tdl.org/jodi/index.php/jodi/article/view/35/37

Murray J. H. (1997). Hamlet on the Holodeck: The Future of Narrative in Cyberspace, Boston, MA: MIT Press.

Poynter Institute (2000). Eye-tracking study conducted by the Poynter Institute and Stanford University.

Prensky M. (2013). Digital Natives, Digital Immigrants. In K. L. Blair, J. Almjeld \& R. M. Murphy (Eds.), Cross Currents: Cultures, Communities, Technologies, Boston, MA: Wadsworth, p. 45-51.

Reinking D., McKenna M. C., Labbo L. D. \& Kieffer R. F. (Eds.) (1998). Handbook of Literacy and Technology: Transformations in a Post-Typographic World, Mahwah, NJ: Lawrence Erlbaum.

Rideout V. J., Foehr U. G., \& Roberts D. F. (2010). Generation $M^{2}$ : Media in the Lives of 8- to 18-Year-Olds. Menlo Park, CA: Henry J. Kaiser Family Foundation. [https://files.eric.ed.gov/fulltext/ED527859.pdf].

Ross C. S. (2002). Reading in a Digital Age. In G. E. Gorman (Ed.), The Digital Factor in Library and Information Services. International Yearbook of Library and Information Management 2002/2003, Lanham, MD: Scarecrow Press, p. 91-111. 
Rowlands I., Nicholas D., Williams P., Huntington P., Fieldhouse M., Gunter B., Withey R., Jamali H. R., Dobrowolski T. \& Tenopir C. (2008). The Google Generation: The Information Behavior of the Researcher of the Future. Aslib Proceedings, Vol. 60, No. 4, 290-310.

Sathe N. A., Grady J. L. \& Giuse N. B. (2002). Print versus Electronic Journals: A Preliminary investigation into the Effect of Journal Format on Research Processes. Journal of the Medical Library Association, Vol. 90, No. 2, p. 235-243.

Siebenberg T. R., Galbraith B.\& Brady E. E. (2004). Print versus Electronic Journal Use in Three Sci/Tech Disciplines: What's Going on Here? College \& Research Libraries, Vol. 65 , No. 5, p. 427-438.

Singer M. L. \& Alexander P. A. (2016): Reading Across Mediums: Effects of Reading Digital and Print Texts on Comprehension and Calibration. The Journal of Experimental Education, Vol. 85, No. 1, p. 155-172.

[https://www.tandfonline.com/doi/full/10.1080/00220973.2016.1143794].

Smith E. T. (2003). Changes in Faculty Reading Behaviors: The impact of electronic journals on the University of Georgia. Journal of Academic Librarianship, Vol. 29, No. 3, p. 162-168.

Stephens W. S. (2010). Books are more than files: teens skeptical about ereading. Voice of Youth Advocates, June 2010, p. 124-125.

Ting Y.-L. (2015). Tapping into Students' Digital Literacy and Designing Negotiated Learning to Promote Learner Autonomy, The Internet and Higher Education, Vol. 26, p. 25-32.

Wallis C. (2010). The Impacts of Media Multitasking on Children's Learning and Development: Report from a research seminar. New York, NY: The Joan Ganz Cooney Center at Sesame Workshop, January 2010 [http://joanganzcooneycenter.org/wpcontent/uploads/2010/03/mediamultitaskingfinal_030510.pdf]. 


\section{Appendix}

\section{A survey questionnaire on the use of print and digital reading materials in education}

Introduction: This questionnaire is part of a doctoral research, which aims to examine university students' reading practices and preferences of using print and digital reading materials in education in Morocco.

Instructions: please answer the following questions by checking $(\checkmark)$ "only" one relevant box among the below options.

\section{Section A: Demographic information}

Age:

Gender: $\square$ Male $\square$ Female

Discipline/filière :

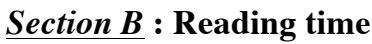

1. How much time do you spend on reading digital documents/sources?

More time $\quad \square$ less time $\quad \square$ do not know

2. How much time do you spend on reading print documents/sources?

More time $\quad \square$ less time $\quad \square$ do not know

\section{Section $C:$ Medium usage}

3. Which reading platform do you use for academic reading?

Print media (books, handouts) $\square$ electronic media (iPads, tablets, smartphones, laptops...etc.)

4. Which reading platform do you use for leisure reading?

$\square$ Print media (books, handouts) $\square$ electronic media (iPads, tablets, smartphones, laptops...etc.) 


\section{Section D: Frequency of using print and digital resources}

5. How frequently do you use digital resources for your studies?
Very often
$\square$ frequently
$\square$ occasionally
$\square$ never

6. How frequently do you use print resources for your studies?
Very often
$\square$ frequently
$\square$ occasionally
$\square$ never

\section{Section E: Screen reading habits}

7. How would you describe your browsing and scanning when using digital texts?
Increasing
$\square$ decreasing
$\square$ do not know

8. How would you describe searching for keywords when using digital materials?

Increasing
$\square$ decreasing
do not know

9. How would you describe your selective reading when using digital materials?
Increasing
decreasing
$\square$ do not know

10. How is your non-linear reading (reading by jumping from line to line, or section to section) with digital materials?
Increasing
$\square$ decreasing
do not know

11. How would you describe your attention when using digital materials?
Increasing
$\square$ decreasing
do not know

12. How would you describe your in-depth reading when using digital materials?
Increasing
$\square$ decreasing
do not know

13. How would you describe your attention when you using digital materials?
Increasing
$\square$ decreasing
$\square$ do not know 
Section F : Frequency of highlighting and multitasking in print and digital materials

14. How frequently do you highlight print documents during reading?
Very often
$\square$ frequently
$\square$ occasionally
$\square$ never

15. How frequently do you highlight digital documents during reading?
Very often
$\square$ frequently
$\square$ occasionally
$\square$ never

16. How frequently do you print out digital reading materials?
Very often
$\square$ frequently
$\square$ occasionally
$\square$ never

17. How often do you multitask (doing two or more tasks at the same time) when you use print materials?
Very often
$\square$ frequently
$\square$ occasionally
$\square$ never

18. How often do you multitask when you use digital materials?
Very often
$\square$ frequently
$\square$ occasionally
$\square$ never

\section{Section $G$ : Preference of reading formats}

19. What is your favorite reading platform?

$\square$ Print media (books, handouts)

$\square$ Electronic media (tablets, laptops...)

$\square$ both are good 